\title{
Sexual activity diminishes male virility in two Coccinella species: consequences for female fertility and progeny development
}

\author{
J.P. Michaud ${ }^{1 *}$, Mahadev Bista ${ }^{2}$, Geetanjali Mishra ${ }^{2}$ \\ and Omkar Singh ${ }^{2}$
}

\author{
${ }^{1}$ Department of Entomology, Kansas State University, Agricultural Research \\ Station-Hays, Hays, KS, USA: ${ }^{2}$ Ladybird Research Laboratory, Department \\ of Zoology, University of Lucknow, Lucknow, India
}

\begin{abstract}
Male contributions, both chemical and behavioural, can influence female sperm usage and reproductive success. To determine whether such male factors are subject to depletion in Coccinella septempunctata and Coccinella transversalis, we tested the effects of male mating history on male virility, as estimated by measures of mating behaviour, female reproductive success and progeny fitness, with parental age held constant. Overt measures of male mating effort (wriggling duration, number of shaking bouts and total copula duration) all diminished from virgin to $5 \times$ mated males and were mirrored by concurrent declines in female fecundity and fertility (measured over 20 days). Paternal effects were also observed which diminished as a function of mating history, suggesting that transgenerational signals of male origin are also subject to depletion. Progeny of virgin fathers had higher rates of survival (C. transversalis) and faster development (both species) than progeny of $5 \times$ mated fathers. Seminal fluid proteins are known to have allohormonal properties and can stimulate female fecundity and fertility in a number of insects, making them strong candidates for depletion as a function of mating activity. However, it is also possible that sperm limitation and/or reduced tactile stimulation of females by multiplemated males may have contributed to some of the observed effects.
\end{abstract}

Keywords: developmental time, fecundity, fertility, paternal effects, seminal fluid proteins

(Accepted 16 March 2013; First published online 17 April 2013)

\section{Introduction}

The evolution of the spermatheca in female insects effectively uncoupled fertilization from insemination and gave rise to novel forms of intersexual conflict (Eberhard, 1996). Once females achieved postcopulatory control over sperm utilization, mating per se was no longer a guarantee of paternity for males. Sperm competition and cryptic female choice became important selective forces shaping the

*Author for correspondence

Phone: 785-625-3425

Fax: 785-625-4369

E-mail: jpmi@ksu.edu evolution of secondary male strategies to influence sperm usage patterns in females (Parker \& Simmons, 1989; Eberhard, 1997; Simmons \& Siva-Jothy, 1998; Fisher et al., 2006). Consequently, males of polyandrous insect species evolved a diversity of tactics to foil male competitors (e.g., sperm removal), reduce female receptivity, prevent females from remating (e.g., mate guarding, mating plugs) and stimulate female oviposition and hence rapid sperm utilization (reviewed by Eberhard, 1996; Gillott, 2003; Wedell, 2005). A variety of compounds generally referred to as 'seminal fluid proteins' (SFPs) are produced in insect male accessory glands (Chen, 1984) and can have a wide range of physiological effects on females, ranging from fecundity and fertility stimulation to reduction of female receptivity (Avila et al., 2011). When sperm competition is intense, or when male 
ejaculates contain nutrients or expensive-to-produce SFPs, the costs of ejaculate production can be much higher than once assumed by the 'sperm is cheap' hypothesis of sexual differentiation (Bonduriansky, 2001; Lupold et al., 2010; Perry \& Rowe, 2010; Avila et al., 2011). Furthermore, it has been argued theoretically that if fecundity stimulation by males is sufficiently strong, it will actually attenuate sperm competition among males because those mating with promiscuous females 'cooperatively' fertilize more eggs than those who inseminate monogamous females (Alonzo \& Pizzari, 2010).

Aphidophagous coccinellids are known to obtain fitness benefits from multiple matings (Quinones Pando et al., 2001; Omkar \& Srivastava, 2002; Omkar \& James, 2005; Omkar \& Pervez, 2005; Bind, 2007; Omkar et al., 2010a), particularly when females mate with multiple males (Majerus, 1994; Omkar \& Mishra, 2005a; Srivastava \& Omkar, 2005; but see Haddrill et al., 2007). Although many species produce a spermatophore in the bursa copulatrix of the female (e.g., Obata, 1987; Omkar \& Mishra, 2005b), others such as Cheilomenes sexmaculata (F.) and Coelophora saucia (Mulsant) engage in direct sperm transfer (Omkar et al., 2006) and there is variation in this regard even within coccinellid subfamilies (e.g., Fisher, 1959; Katakura et al., 1994; Kaufmann, 1996). Among spermatophore-forming species, females may or may not eject and consume the spermatophore following termination of copula (e.g., Obata, 1987; Perry \& Rowe, 2010), raising the possibility of a male nutritional contribution, or 'nuptial gift'. However, Eberhard (1997) argues that allohormonal substances in male seminal products tend to have more important effects on female reproduction than nutritional contributions and a study by Perry \& Rowe (2008) suggests that spermatophore consumption by coccinellid females yields little, if any, nutritional benefit. Wilson et al. (1999) attributed elevated fecundity resulting from multiple matings in two bruchid species to the action of 'oviposition stimulants' delivered by males, rather than any nutritional donation and similar female benefits from multiple matings have been demonstrated for Coccinella septempunctata (Bista \& Omkar, 2012).

If ejaculates are costly to produce, the virility of coccinellid males should decline as a function of repeated matings, and that could result in diminished fecundity and/or fertility in their mates. Furthermore, if male seminal products mediate paternal effects, there may be a reduction in offspring quality as a function of paternal mating history. The present study used two congeneric ladybird species, C. septempunctata (L.) and Coccinella transversalis F., to test whether increased male mating activity would affect either the quantity or quality of progeny while controlling for effects of both male and female age. Both species co-occur widely throughout Asia where C. septempunctata contributes to control of aphids on many herbaceous crops (Hodek, 1996; Hodek \& Michaud, 2008), with C. transversalis more specific to legumes and mustards (Hodek, 1996; Yadav et al., 2011). However, females of C. septempunctata eject and consume spermatophores, whereas females of $C$. transversalis eject, but do not consume them, providing an opportunity to control any nutritional effects of spermatophore consumption.

On the basis of the foregoing, we propose two hypotheses with respect to the influence of male virility on female fertility and progeny fitness. We hypothesize that female fecundity and fertility should decline with increasing history of sexual activity in her mate, on the assumption that female reproductive stimulation will represent a physiological expense for males. Second, we hypothesize that some measures of progeny fitness should diminish with increasing history of paternal sexual activity, assuming that there are paternal effects on offspring quality.

\section{Materials and methods}

Insects

Adults of $C$. septempunctata and C. transversalis ( $n \sim 50$ of each species) were collected from agricultural fields around Lucknow, Uttar Pradesh, India, brought to the laboratory and used to establish stock colonies in climate-controlled growth chambers. Physical conditions were set at $27 \pm 1^{\circ} \mathrm{C}, 65 \pm 5 \% \mathrm{RH}$ and 14L:10D photoperiod. Adult beetles were sexed, paired in plastic Petri dishes $(9.0 \times 2.0 \mathrm{~cm})$ and fed cowpea aphids, Aphis craccivora Koch, reared in a glasshouse on cowpea plants, Vigna unguiculata L. All egg clusters were collected daily and isolated in Petri dishes (as above) until hatching. Upon eclosion, larvae were transferred to plastic beakers $(14.5 \times 10.5 \mathrm{~cm}), 10$ per beaker and provisioned with an ad libitum supply of $A$. craccivora on cowpea shoots that were replenished daily until the larvae pupated. Adults for use in experiments were isolated individually in Petri dishes upon emergence and fed cowpea aphids ad libitum, refreshed daily.

\section{Experimental protocol}

Behavioural observations were made on a laboratory bench at $25 \pm 2{ }^{\circ} \mathrm{C}$ under fluorescent lights; otherwise all experimental insects were held under the same physical conditions as the stock colony. In order to determine the effect of mating history on male mating behaviour, maternal reproduction and progeny development, four types of mate crosses $(n=10$ each) were conducted with both $C$. septempunctata and C. transversalis:

(A) 10-day-old virgin female $\times 10$-day-old virgin male.

(B) 10-day-old virgin female $\times 10$-day-old male mated once (on day 9).

(C) 10-day-old virgin female $\times 10$-day-old male mated twice (on days 8 and 9).

(D) 10-day-old virgin female $\times 10$-day-old C. transversalis male mated five times (on days 5-9); 12-day-old C. septempunctata mated five times (on days 7-11).

In a normal mating sequence, males of C. septempunctata initiate a series of vertical thrusting movements with the abdomen (strokes) shortly after genital contact is established with the female. These are followed by wriggling movements (a gentle forward and backward movement of the abdomen with a simultaneous side-to-side component) and then by a series of shaking bouts (rapid lateral oscillations of the abdomen separated by resting intervals. Strokes and wriggling movements are observed only during the initial stages of mating. The mating behaviour of $C$. transversalis is similar in all respects, but lacks the period of vertical strokes.

All matings were subject to continuous direct observation and the following data were recorded: The initial latent period $[=$ time from genital contact to first stroke (C. septempunctata), or to first wriggling movement (C. transversalis)]; number of strokes (C7); number of wriggling movements; total duration of wriggling 

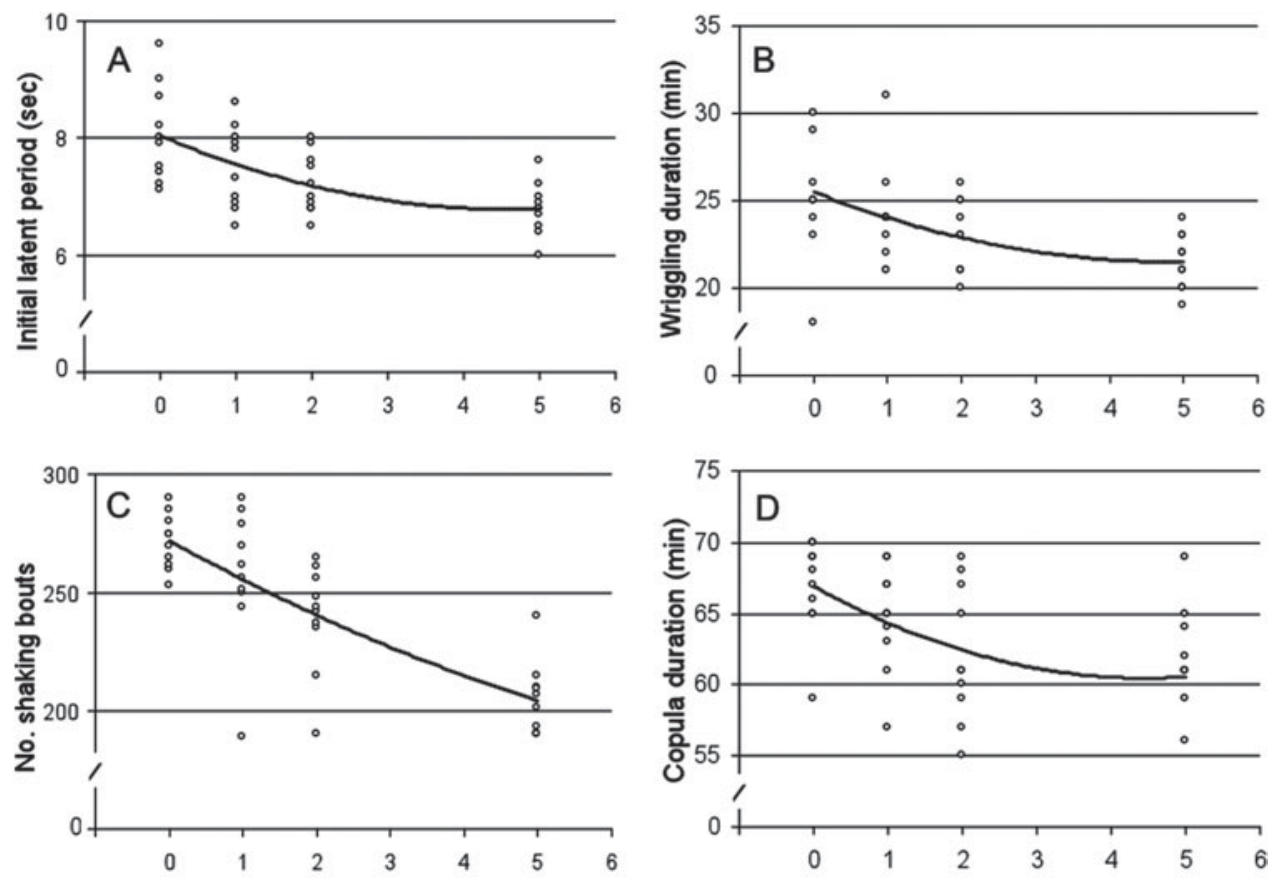

No. previous paternal matings

Fig. 1. Quadratic regression of various components of male mating behaviour for 10 day-old C. septempuntata males of different mating histories $(5 \times$ mated males were 12-day-old) mated with virgin 10-day-old females. See text for behaviour definitions.

movements; number of shaking bouts; total duration of shaking bouts; duration of resting intervals between bouts; terminal latent period (period from last shaking bout until pair separation); and total mating duration (period from initial genital contact until pair separation).

At the end of each mating, the female was isolated in a Petri dish (as above) with an ad libitum supply of $A$. craccivora replenished daily, and her eggs were collected daily for the next 20 days. All the eggs were incubated until eclosion and rates of hatching were recorded. Ten larvae were selected from each experimental female over the first two days of her reproduction and reared to follow progeny development. Neonates were transferred to plastic beakers $(14.5 \times 10.5 \mathrm{~cm}$, 10 per beaker) covered with muslin secured with a rubber band and provisioned daily with an ad libitum supply of cowpea aphids on plant shoots. Developmental time (from egg to adult emergence) and stage-specific mortality data were recorded for each replicate.

\section{Statistical analysis}

All data were subjected to regression analysis and trend lines were fit using non-linear regression; in all cases, quadratic equations provided lines of best fit.

\section{Results}

\section{C. septempunctata}

There was a significant effect of male mating history on length of the initial latent period $\left(F_{1,37}=10.79, P<0.001\right.$, $\left.R^{2}=0.368\right)$; more matings resulted in shorter initial latent periods (fig. 1a). Male mating history did not affect the number of strokes prior to wriggling $\left(F_{1,37}=1.56, P=0.224\right.$, means $\pm S E=101.6 \pm 5.03)$. However, more matings decreased the duration of wriggling movements $\left(F_{1,37}=6.22, P=0.005\right.$, $R^{2}=0.252$, fig. $\left.1 \mathrm{~b}\right)$ and the number of shaking bouts $\left(F_{1,37}=30.06, P<0.0001, R^{2}=0.619\right.$, fig. $\left.1 c\right)$. There was no effect of male mating history on either the time spent in resting intervals between shaking bouts (means $\pm S E=22.0 \pm$ $0.9,21.4 \pm 1.0,21.4 \pm 1.2$ and $18.4 \pm 2.2 \mathrm{~min}$ for $0 \times, 1 \times 2 \times$ and $5 \times$ mated males, respectively; $F_{1,37}=2.82, P=0.072$ ), or in the duration of the terminal latent period (means $\pm S E=22.9 \pm 0.6$, $22.8 \pm 0.8,22.5 \pm 0.7$ and $22.1 \pm 0.6 \mathrm{~s}$ for $0 \times, 1 \times, 2 \times$ and $5 \times$ mated males, respectively; $F_{1,37}=0.32, P=0.729$ ), but more previous male matings diminished the duration of copula overall $\left(F_{1,37}=5.71, P=0.007, R^{2}=0.236\right.$, fig. $\left.1 \mathrm{~d}\right)$. Preoviposition periods (means $\pm S E$ ) averaged $4.0 \pm 0.2,3.7 \pm 0.4$, $3.8 \pm 0.2$ and $4.5 \pm 0.3$ days for females mated to males with $0,1,2$ and 5 previous matings, respectively $(F=1.29 ; \mathrm{df}=3,36$; $P=0.176$ ). The number of eggs laid by females over a 20 -day period declined as the mating history of their males increased ( $F_{1,37}=4.97, P=0.012, R^{2}=0.212$, fig. $2 a$ ) and so did their fertility $\left(F_{1,37}=146.19, P<0.0001, R^{2}=0.888\right.$, fig. $\left.2 b\right)$.

Immature survival (from eclosion to adult emergence) appeared to decline as a function of paternal mating history, but the regression was not significant $(F=1.92 ; \mathrm{df}=3,39$; $P=0.144$; fig. 2c). However, more paternal matings significantly increased total developmental time of progeny $\left(F_{1,37}=20.02, P<0.0001, R^{2}=0.520\right.$, fig. $\left.2 \mathrm{~d}\right)$, due to increases in the duration of the incubation period $\left(F_{1,37}=8.05, P=0.001\right)$, the first instar $\left(F_{1,37}=6.06, P=0.005\right)$, and the fourth instar $\left(F_{1,37}=4.57, P=0.017\right)$. 

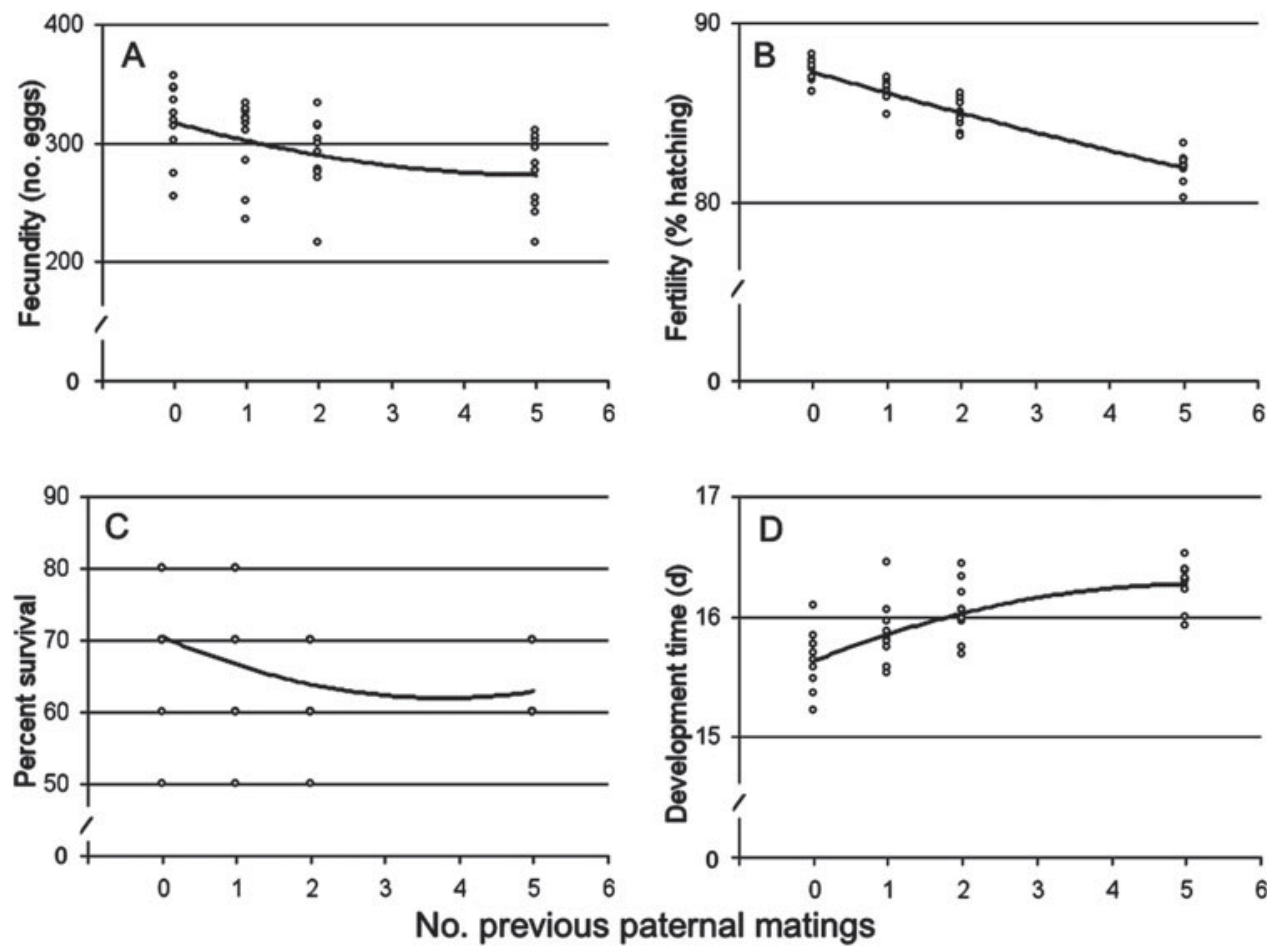

Fig. 2. Quadratic regression of reproductive data and development of progeny produced during the first five days of oviposition by 10-dayold C. septempuntata females mated as virgins with 10 -day-old males of different mating histories $(5 \times$ mated males were 12 -day-old).

\section{C. transversalis}

There was a significant effect of male mating history on length of the initial latent period $\left(F_{1,37}=39.10, P<0.0001\right.$, $\left.R^{2}=0.679\right)$; more matings resulted in shorter initial latent periods (fig. 3a). More matings decreased the duration of wriggling movements $\left(F_{1,37}=4.06, P=0.025, R^{2}=0.18\right.$, fig. $\left.3 \mathrm{~b}\right)$ and the number of shaking bouts $\left(F_{1,37}=20.62, P<0.0001\right.$, $R^{2}=0.527$, fig. $3 \mathrm{c}$ ) and resulted in longer periods spent in resting intervals (means $\pm \mathrm{SE}=12.0 \pm 0.1,12.2 \pm 0.2,12.4 \pm 0.1$ and $12.5 \pm 0.1 \mathrm{~min}$ for $0 \times, 1 \times, 2 \times$ and $5 \times$ mated males, respectively; $\left.F_{1,37}=5.34, P=0.009, R^{2}=0.224\right)$. The total duration of copula decreased as the number of previous male matings increased $\left(F_{1,37}=21.26, P<0.0001, R^{2}=0.535\right.$ fig. $\left.3 \mathrm{~d}\right)$, although there was no effect of mating history on the terminal latent period (means $\pm \mathrm{SE}=8.1 \pm 0.3,8.6 \pm 0.3,8.4 \pm 0.2$ and $7.8 \pm 0.3 \mathrm{~min}$ for $0 \times, 1 \times, 2 \times$ and $5 \times$ mated males, respectively; $\left.F_{1,37}=1.97, P=0.154\right)$. There was a tendency for preoviposition period (means $\pm \mathrm{SE}$ ) to lengthen as the number of previous male matings increased from 0 to $5(1.9 \pm 0.3,2.4 \pm 0.3,2.9 \pm 0.3$ and $3.1 \pm 0.5)$, but means did not differ significantly $\left(F_{3,39}=2.31, P=0.093\right)$. As in C. septempunctata, the number of eggs laid by females in a 20-day period declined as the mating experience of their males increased $\left(F_{1,37}=15.81, P<0.0001\right.$, $R^{2}=0.461$, fig. $\left.4 \mathrm{a}\right)$ and so did their fertility $\left(F_{1,37}=54.57\right.$, $P<0.0001, R^{2}=0.747$, fig. $4 \mathrm{~b}$ ).

Immature survival (1st instar to adult) diminished as the number of paternal matings increased $\left(F_{3,39}=4.60, P=0.008\right.$, fig. 4c). More paternal matings also increased total developmental time of progeny $\left(F_{1,37}=15.76, P<0.0001, R^{2}=0.460\right.$, fig. 4d), due largely to increases in the duration of the incubation period $\left(F_{1,37}=12.12, P<0.001\right)$, and the fourth instar $\left(F_{1,37}=6.42, P=0.004\right)$.

\section{Discussion}

The fecundity and fertility of females of both species were affected by paternal mating history, as hypothesized, indicating that male sexual activity diminishes male virility as reflected in female reproductive success. Notably, betweentreatment variation in number of shaking bouts, duration of wriggling behaviour and overall duration of copula mirrored variation in female fecundity and fertility, suggest that these male behaviours correlate with male mating effort and differences in female reproductive performance. In both species, the number of shaking bouts was diminished by approximately $30 \%$ in $5 \times$ mated males compared with virgins, although the corresponding reduction in female fecundity was proportionally greater in C. transversalis, the more fecund species.

Insect seminal fluids are very complex and may contain a large number of substances (Reinhardt et al., 2009). If males use seminal fluids to stimulate female reproductive activity, these products may become depleted in males over the course of multiple matings. Alternatively, depletion of sperm itself might contribute to the observed results, if sperm have a direct stimulatory effect on female reproductive processes. Heifetz et al. (2001) used mutant males of Drosophila melanogaster deficient in male accessory gland proteins and/or sperm to demonstrate that both factors exert complimentary effects on the onset and rate of female oogenesis. In subsequent work, Heifetz \& Wolfner (2004) demonstrated different neurological responses of the female reproductive tract to sperm, accessory gland proteins and either mechanical mating stimulation or some other unknown seminal fluid component. Since the duration of copula and numbers of shaking bouts in these 

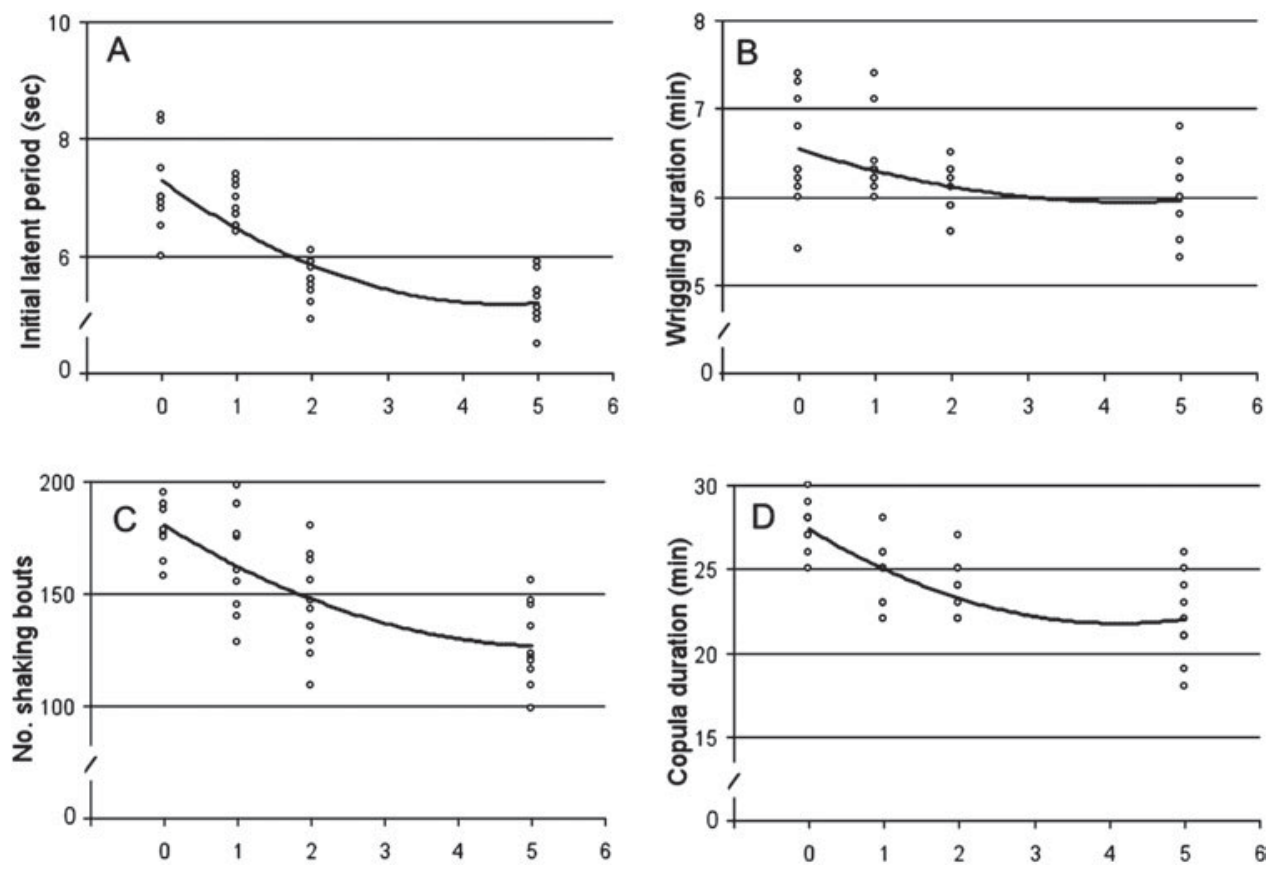

Fig. 3. Quadratic regression of various components of male mating behaviour for 10-day-old C. transversalis males of different mating histories mated with virgin 10-day-old females. See text for behaviour definitions.
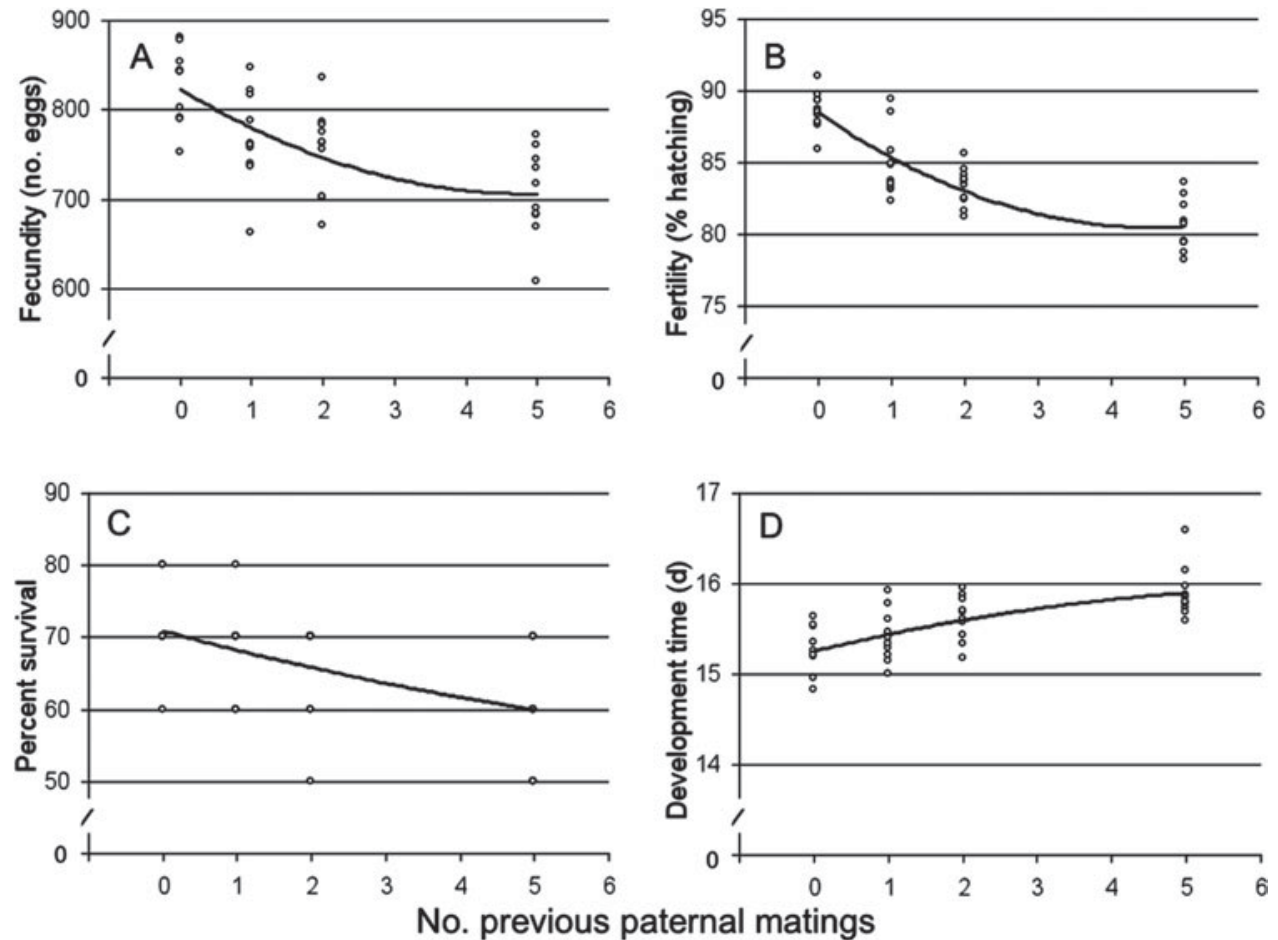

Fig. 4. Quadratic regression of reproductive data and development of progeny produced during the first five days of oviposition by 10-dayold C. transversalis females mated as virgins with 10-day-old males of different mating histories.

Coccinella spp. also diminished as a function of previous matings, tactile stimulation of the female would also have been reduced and, if such stimulation has neurosecretory consequences, this may have contributed also to the reduced reproductive success of females mated to nonvirgin males. 
The similarity of responses in both species suggest the observed effects on female reproduction are not related to spermatophore consumption, as $C$. transversalis females do not consume them, even though those of $C$. septempunctata do. Previously, Omkar et al. (2006) examined mating duration in $C$. sexmaculata and $C$. saucia and found that preoviposition periods became shorter and fecundities increased as females were permitted to mate for longer periods, suggesting a progressive transfer of seminal fluids to the female during copula. In the latter species, female fecundity was also shown to decline as a function of male age at mating (Omkar et al., 2010b), suggesting that male virility declines with age. Perry \& Rowe (2010) showed that low-condition Adalia bipunctata L. males produced ejaculates with higher relative sperm content, suggesting they reduced non-sperm components of seminal fluid more than sperm under conditions of resource limitation. If nonsperm components of seminal fluids are more costly to produce than the sperm itself, depletion of these materials may limit coccinellid male fertility more than the rate of spermatogenesis. Such is the case for the bed bug, Cimex lectularius L. (Reinhardt et al., 2011) despite a very different fertilization mechanism (traumatic insemination).

Although it would make sense for coccinellid females to lay only eggs that have sperm available to fertilize them, they do not have perfect control over the fertilization process. For example, a short (10s) period of mating in C. sexmaculata and C. saucia is not enough to permit sperm transfer in these species and yet it still stimulates some oviposition of infertile eggs by females (Omkar et al., 2006). The observed changes in egg fertility as a function of increased male mating history in these experiments may reflect either qualitative (sperm viability) or quantitative (sperm number) effects, or some combination thereof. Repeated matings may also deplete males of factors associated with sperm activation, storage, or nourishment (Poiani, 2006). Yaginuma et al. (1996) demonstrated that structural proteins of the Tenebrio molitor L. spermatophore and associated sugars may be implicated in both the activation of sperm in the bursa copulatrix of female, and their subsequent nourishment in the spermatheca. Other studies have identified sex peptides of male origin in Diptera and Lepidoptera that trigger neuroendocrinal responses in females (Chen et al., 1988; Hanin et al., 2012; LaFlamme et al., 2012). Work on both Danaus plexippus (L.) (Herman, 1993) and Tribolium castaneum (Herbst) (Parthasarathy et al., 2009) has implicated juvenile hormone as an important factor mediating the expression of accessory gland proteins and their resulting effects on female fertility. The present results indicate that Coccinella spp. males are able to affect female fertility and fecundity, presumably for their own benefit, but this capacity is significantly diminished as a function of mating activity.

Male mating history also had effects on offspring fitness, although the magnitude of the effects were not great, indicating paternal effects on offspring survival and development that are likewise diminished as a function of male sexual activity. The trend towards a reduction in progeny survival by about $10 \%$ after five paternal matings was significant only in C. transversalis, due to high within-treatment variation in C. septempunctata (figs $2 \mathrm{c}$ and $4 \mathrm{c}$ ). However, there was a significant increase in the developmental time of offspring in both species with increased paternal matings (figs $2 \mathrm{~d}$ and $4 \mathrm{~d}$ ), suggesting that seminal fluids contain allohormonal factors that either serve to accelerate offspring development directly, or trigger maternal responses that have this effect. Although the difference in developmental time across treatments was slightly less than one day in both species, even small delays in development can have negative consequences for aphidophagous coccinellids. Fast progeny development is especially important to parental fitness in these species because developmental time is negatively correlated with body size and larvae must exploit ephemeral prey, usually aphids, to achieve a critical pupation weight within a narrow time window (Kindlmann \& Dixon, 1993).

Most studies of transgenerational phenotypic plasticity in insects have examined maternal effects, the epigenetic mechanisms whereby females can affect phenotype development in their progeny. Although the existence of maternal effects has been recognized for nearly 80 years (Dobzhansky, 1935), it is only since the publication of Mousseau \& Fox (1998) that they have become the focus of significant research attention, especially in insects (Fox \& Mousseau, 1998; Mousseau et al., 2009). However, paternal effects have received less attention, despite the fact that male insects often influence female reproductive physiology (reviewed in Ridley, 1988; Alexander et al., 1997), and hence potentially the development of their progeny. For example, female condition had no effect on progeny body size in the neriid fly Telostylinus angusticollis (Enderlein), but the offspring of high-condition males were larger than those of low-condition males (Bonduriansky \& Head, 2007). The herbivorous coccinellid Epilachna paenulata Germar synthesizes defensive alkaloids which both parents contribute to the eggs (Camarano et al., 2009). Previous studies on Coleomegilla maculata (DeGeer) and Hippodamia convergens GuerinMeneville have demonstrated effects of maternal age on progeny development and examined how maternal body size can act as a constraint on these signals (Vargas et al., 2012a, $b$, $c)$. However, since body size was manipulated simultaneously in both males and females in these studies, it seems likely that paternal effects contributed at least partly to some results, such as the rapidly declining fertility observed in pairs of small $H$. convergens beetles (Vargas et al., 2012b).

The multiple effects of male factors on female fecundity, fertility and progeny fitness may select abilities in coccinellid females to distinguish male mating status and discriminate, either overtly or cryptically, in favour of virgin males. Female coccinellids often exert mate preference based on genetic or phenotypic criteria (O'Donald \& Majerus, 1984; Wang et al., 2009; Wang et al., 2013) and when subclasses of males are disfavoured, this can theoretically lead to differential patterns of male investment in sperm versus seminal fluids (Cameron et al., 2007). Similarly, if matings exact a cost in terms of male virility, we might expect selection of males to discriminate female mating status and adjust their mating effort accordingly. Since some sperm mixing occurs within multiply-mated coccinellid females (de Jong et al., 1998; Haddrill et al., 2008) males may invest more reproductive effort in virgins than in previously mated females. Future experiments could test for male age-mating status interactions and effects of male condition on paternal effects. Furthermore, body size has a range of reproductive consequences in coccinellids (e.g., Vargas et al., 2012a, b, c) and its possible effects on male virility have not yet been explored. Subsequent experiments could test for effects of body size on male virility and for abilities of both sexes to detect the mating status of sexual partners and alter reproductive investment accordingly. 


\section{Acknowledgements}

The authors thank the Department of Higher Education, Government of Uttar Pradesh, for financial assistance under the Centre of Excellence Programme. MB was supported by a fellowship from the University Grants Commission, Government of Nepal contribution number 13-147-J of the Kansas State Agricultural Experiment Station.

\section{References}

Alexander, R.D., Marshall, D.C. \& Cooley, J.R. (1997) Evolutionary perspectives on insect mating. pp. 4-31 in Choe, J.C. \& Crespi, B.J. (Eds) The Evolution of Mating Systems in Insects and Arachnids. Cambridge, UK, Cambridge University Press.

Alonzo, S. \& Pizzari, T. (2010) Male fecundity stimulation: conflict and cooperation within and between the sexes: model analyses and coevolutionary dynamics. American Naturalist 175, 174-185.

Avila, F.W., Sirot, L.K., LaFlamme, B.A., Rubinstein, C.D. \& Wolfner, M.F. (2011) Insect seminal fluid proteins: identification and function. Annual Review of Entomology 56, 21-40.

Bind, R.B. (2007) Reproductive behaviour of a generalist aphidophagous ladybird beetle Cheilomenes sexmaculata (Coleoptera: Coccinellidae). International Journal of Tropical Insect Science 27, 77-84.

Bista, M. \& Omkar (2012) Impact of multiple mating on behavioural patterns and reproductive attributes of seven spotted ladybird beetle, Coccinella septempunctata (L.). Journal of Applied Bioscience 38, 159-164.

Bonduriansky, R. (2001) The evolution of male mate choice in insects: a synthesis of ideas and evidence. Biological Reviews 76, 305-339.

Bonduriansky, R. \& Head, M. (2007) Maternal and paternal condition effects on offspring phenotype in Telostylinus ngusticollis (Diptera: Neriidae). Journal of Evolutionary Biology 20, 2379-2388.

Camarano, S., Andres, G. \& Carmen, R. (2009) Biparental endowment of endogenous defensive alkaloids in Epilachna paenulata. Journal of Chemical Ecology 35, 1-7.

Cameron, E., Day, T. \& Rowe, L. (2007) Sperm competition and the evolution of ejaculate composition. American Naturalist 169, E158-E172.

Chen, P.S. (1984) The functional morphology and biochemistry of insect male accessory glands and their secretions. Annual Review of Entomology 29, 233-255.

Chen, P.S., Strumm-Zollinger, E., Aigaki, T., Balmer, J., Bienz, M. \& Bohlen, P. (1988) A male accessory gland peptide that regulates reproductive behavior of female Drosophila melanogaster. Cell 54, 291-298.

de Jong, P.W., Brakefield, P.M., Geerinck, B.P. (1998) The effect of female mating history on sperm precedence in the twospot ladybird, Adalia bipunctata (Coleoptera: Coccinellidae). Behavorial Ecology 9, 559-565.

Dobzhansky, T. (1935) Maternal effect as a cause of the difference between the reciprocal crosses in Drosophila pseudoobscura. Proceedings of the National Academy of Sciences of the United States of America 21, 443-446.

Eberhard, W.G. (1996) Female Control: Sexual Selection by Cryptic Female Choice. Princeton, NJ, Princeton University Press.

Eberhard, W.G. (1997) Sexual selection by cryptic female choice in insects and arachnids. pp. 32-57 in Choe, J.C. \& Crespi, B.J.
(Eds) The Evolution of Mating Systems in Insects and Arachnids. Cambridge, UK, Cambridge University Press.

Fisher, D.O., Double, M.C., Blomberg, S.P., Jennions, M.D. \& Cockburn, A. (2006) Post-mating sexual selection increases lifetime fitness of polyandrous females in the wild. Nature 444, 89-92.

Fisher, T.W. (1959) Occurrence of spermatophore in certain species of Chilocorus. Pan-Pacific Entomologist 35, 205-208.

Fox, C.W. \& Mousseau, T.A. (1998) Maternal effects as adaptations for transgenerational phenotypic plasticity in insects. pp. 159-177 in Mousseau, T. \& Fox, C. (Eds), Maternal Effects as Adaptations. Oxford, UK, Oxford University Press.

Gillott, C. (2003) Male accessory gland secretions: modulators of female reproductive physiology and behavior. Annual Review of Entomology 48, 163-184.

Haddrill, P.R., Shuker, D.M., Mayes, S. \& Majerus, M.E.N. (2007) Temporal effects of multiple mating on components of fitness in the two-spot ladybird, Adalia bipunctata (Coleoptera: Coccinellidae). European Journal of Entomology 104, 393-398.

Haddrill, P.R., Shuker, D.M., Amos, W., Majerus, M.E.N. \& Mayes, S. (2008) Female multiple mating in wild and laboratory populations of the two-spot ladybird, Adalia bipunctata. Molecular Ecology 17, 3189-3197.

Hanin, O., Azrielli, A., Applebaum, S.W. \& Rafaeli, A. (2012) Functional impact of silencing the Helicoverpa armigera sexpeptide receptor on female reproductive behaviour. Insect Molecular Biology 21, 161-167.

Heifetz, Y. \& Wolfner, M.F. (2004) Mating, seminal fluid components, and sperm cause changes in vesicle release in the Drosophila female reproductive tract. Proceedings of the National Academy of Sciences Series B 101, 6261-6266.

Heifetz, Y., Tram, U. \& Wolfner, M.F. (2001) Male contributions to egg production: the role of accessory gland products and sperm in Drosophila melanogaster. Proceedings of the Royal Society of London. Series B. Biological Sciences 268, 175-180.

Herman, W.S. (1993) Endocrinology of the monarch butterfly. Natural History Museum of Los Angeles County Science Series 38, 143-146.

Hodek, I. (1996) Food relationships. pp. 143-238 in Hodek, I \& Honek, A. (Eds) Ecology of Coccinellidae. Dordrecht, Netherlands, Kluwer Academic Publishers.

Hodek, I. \& Michaud, J.P. (2008) Why is Coccinella septempunctata so successful? European Journal of Entomology 105, 1-12.

Katakura, H., Nakano, S., Hosogai, T. \& Kahono, S. (1994) Female internal reproductive organs, modes of sperm transfer, and phylogeny of Asian Epilachninae (Coleoptera: Coccinellidae). Journal of Natural History 28, 577-583.

Kaufmann, T. (1996) Dynamics of sperm transfer, mixing, and fertilization in Cryptolaemus montrouzieri (Coleoptera: Coccinellidae) in Kenya. Annals of the Entomological Society of America 89, 238-242.

Kindlmann, P. \& Dixon, A.F.G. (1993) Optimal foraging in ladybird beetles (Coleoptera: Coccinelidae) and its consequences in their use in biological control. European Journal of Entomology 90, 443-450.

LaFlamme, B.A., Ram, K.R. \& Wolfner, M.F. (2012) The Drosophila melanogaster seminal fluid protease 'seminase' regulates proteolytic and post-mating reproductive processes. Public Library of Science Genetics 8, e10002435.

Lupold, S., Manier, M.K., Ala-Honkola, O., Belote, J.M. \& Pitnick, S. (2010) Male Drosophila melanogaster adjust ejaculate size based on female mating status, fecundity, and age. Behavioral Ecology 22, 184-191. 
Majerus, M.E.N. (1994) Female promiscuity maintains high fertility in ladybirds (Col., Coccinellidae). Entomologist's Monthly Magazine 130, 1564-1567.

Mousseau, T.A. \& Fox, C.W. (Eds) (1998) Maternal Effects as Adaptations. Oxford, UK, Oxford University Press.

Mousseau, T.A., Uller, T., Wapstra, E. \& Badyaev, A.V. (2009) Evolution of maternal effects: past and present. Philosophical Transactions of the Royal Society of London Series B, Biological Sciences 364, 1035-1038.

Obata, S. (1987) Mating behaviour and sperm transfer in the ladybird beetle, Harmonia axyridis Pallas (Coleoptera: Coccinellidae). Applied Entomological Zoology 22, 434-442.

O'Donald, P. \& Majerus, M.E.N. (1984) Polymorphism of melanic ladybirds maintained by frequency-dependent sexual selection. Biological Journal of the Linnean Society 23, 101-111.

Omkar \& James, B.E. (2005) Reproductive behaviour of an aphidophagous ladybeetle Coccinella transversalis (Coleoptera: Coccinellidae). International Journal of Tropical Insect Science 25, 96-102.

Omkar \& Mishra, G. (2005a) Evolutionary significance of promiscuity in an aphidophagous ladybird, Propylea dissecta (Coleoptera: Coccinellidae). Bulletin of Entomological Research 95, 527-533.

Omkar \& Mishra, G. (2005b) Mating in aphidophagous ladybirds: costs and benefits. Journal of Applied Entomology 129, 432-436.

Omkar \& Pervez, A. (2005) Mating behavior of an aphidophagous ladybird beetle, Propylea dissecta (Mulsant). Journal of Insect Science 12, 37-44.

Omkar \& Srivastava, S. (2002) The reproductive behaviour of an aphidophagous ladybeetle, Coccinella septempunctata (Coleoptera: Coccinellidae). European Journal of Entomology 99, 465-470.

Omkar, Singh, S.K. \& Pervez, A. (2006) Influence of mating duration on fecundity and fertility in two aphidophagous ladybirds. Journal of Applied Entomology 130, 103-107.

Omkar, Singh, S.K. \& Mishra, G. (2010a) Multiple matings affect the reproductive performance of the aphidophagous ladybird beetle, Coelophora saucia (Coleoptera: Coccinellidae). European Journal of Entomology 107, 177-182.

Omkar, Singh, S.K. \& Mishra, G. (2010b) Parental age at mating affects reproductive attributes of the aphidophagous ladybird beetle, Coelophora saucia (Coleoptera: Coccinellidae). European Journal of Entomology 107, 341-347.

Parker, G.A. \& Simmons, L.W. (1989) Nuptial feeding in insects: theoretical models of male and female interests. Ethology 82, 3-26.

Parthasarathy, R., Tan, A., Sun, Z., Chen, Z., Rankin, M. \& Palli, S.R. (2009) Juvenile hormone regulation of male accessory gland activity in the red flour beetle, Tribolium castaneum. Mechanisms of Development 126, 563-579.

Perry, J.C. \& Rowe, L. (2008) Ingested spermatophores accelerate reproduction and increase mating resistance but are not a source of sexual conflict. Animal Behaviour 76, 993-1000.

Perry, J.C. \& Rowe, L. (2010) Condition-dependent ejaculate size and composition in a ladybird beetle. Proceedings of the Royal Society of London. Series B. Biological Sciences 1700, 3639-3647.

Poiani, A. (2006) Complexity of seminal fluid: a review. Behavioral Ecology and Sociobiology 60, 289-310.
Quinones Pando, F.J., Chavez-Sanchez, N. \& Tarango Rivero, S. H. (2001) Effect of the time of availability of the male in the fecundity of Harmonia axyridis Pallas (Coleoptera: Coccinellidae). Folio Entomologica Mexicana 40, 47-52.

Reinhardt, K., Wong, C.H. \& Georgiou, A.S. (2009) Seminal fluid proteins in the bed bug, Cimex lectularius, detected using two-dimensional gel electrophoresis and mass spectrometry. Parasitology 136, 283-292.

Reinhardt, K., Naylor, R. \& Siva-Jothy, M.T. (2011) Male mating rate is constrained by seminal fluid availability in bedbugs, Cimex lectularius. Public Library of Science One 6, e22082.

Ridley, M. (1988) Mating frequency and fecundity in insects. Biological Reviews 63, 509-549.

Simmons, L.W. \& Siva-Jothy, M.T. (1998) Sperm competition in insects: mechanisms and potential for selection. pp. 341-434 in Birkhead, T.R. \& Moller, A.P. (Eds) Sperm Competition and Sexual Selection. San Diego, CA, USA, Academic Press.

Srivastava, S. \& Omkar (2005) Short- and long-term benefits of promiscuity in the seven-spotted ladybird Coccinella septempunctata (Coleoptera: Coccinellidae). International Journal of Tropical Insect Science 25, 176-181.

Vargas, G., Michaud, J.P. \& Nechols, J.R. (2012a) Maternal effects shape dynamic trajectories of reproductive allocation in the ladybird Coleomegilla maculata. Bulletin of Entomological Research 102, 558-565.

Vargas, G., Michaud, J.P. \& Nechols, J.R. (2012b) Larval food supply constrains female reproductive schedules in Hippodamia convergens (Coleoptera: Coccinellidae). Annals of the Entomological Society of America 105, 832-839.

Vargas, G., Michaud, J.P. \& Nechols, J.R. (2012c) Cryptic maternal effects in Hippodamia convergens (Coleoptera: Coccinellidae) vary with maternal age and body size. Entomologia Experimentalis et Applicata 146, 302-311.

Wang, S., Michaud, J.P., Zhang, R., Zhang, F. \& Liu, S. (2009) Seasonal cycles of assortative mating and reproductive behaviour in polymorphic populations of Harmonia axyridis in China. Ecological Entomology 34, 483-494.

Wang, S., Michaud, J.P., Tan, X.L., Murray, L. \& Zhang, F. (2013) Melanism in a Chinese population of Harmonia axyridis (Coleoptera: Coccinellidae): A citerion for male investment with pleiotropic effects on behavior and fertility. Journal of Insect Behavior (in press).

Wedell, N. (2005) Female receptivity in butterflies and moths. Journal of Experimental Biology 208, 3433-3440.

Wilson, N., Tufton, T.J. \& Eady, P.E. (1999) The effect of single, double, and triple matings on the lifetime fecundity of Callosobruchus analis and Callosobruchus maculatus (Coleoptera: Bruchidae). Journal of Insect Behavior 12, 295-306.

Yadav, R., Yadav, N., Yadav, R. \& Katiyar, R.R. (2011) Predation by various predators on major insect pests of field crops in Uttar Pradesh. Journal of Experimental Zoology 14, 637-638.

Yaginuma, T., Mizuno, T., Mizuno, C., Wada, T., Hattori, K., Yamashita, O. \& Happ, G.M. (1996) Trehalase in the spermatophore from the bean-shaped accessory gland of the male mealworm beetle, Tenebrio molitor: Purification, kinetic properties and localization of the enzyme. Journal of Comparative Physiology. B, Biochemical, Systemic, and Environmental Physiology 166, 1-10. 